\title{
The Learning Network on Sustainability: an e-mechanism for the development and diffusion of teaching materials and tools on Design for Sustainability in an open-source and copy left ethos
}

\section{Carlo Vezzoli and Fabrizio Ceschin*}

Politecnico di Milano, INDACO Department, Unit of Research Design and System Innovation for Sustainability (DIS), via Durando 38/A,

20158 Milan, Italy. E-mail: carlo.vezzoli@polimi.it;

fabrizio.ceschin@polimi.it.

*Corresponding author

\begin{abstract}
This paper presents the intermediate results of the Learning Network on Sustainability (LeNS) project, Asian-European multi-polar network for curricula development on Design for Sustainability. LeNS is a mechanism to develop and diffuse system design for sustainability in design schools with a transcultural perspective. The main output of the project is the Open Learning E-Package (OLEP), an open web-platform that allows a decentralised and collaborative production and fruition of knowledge. Apart from the contents, the same LeNS web-platform is realised in an open-source and copy left ethos, allowing its download and reconfiguration in relation to specific needs, interests and geographical representation.
\end{abstract}

Keywords: e-learning; learning network; sustainability; didactic materials and tools; learning objects; collaborative knowledge production; open-source; copy left; design for sustainability; product-service system; PSS.

Reference to this paper should be made as follow: Vezzoli, C. and Ceschin, F. (20xx) 'The Learning Network on Sustainability: an e-mechanism for the development and diffusion of teaching materials and tools on Design for Sustainability in an open-source and copy left ethos' Int. J. Management in Education, Vol. $x$, No. x, pp.xxx-xxx.

Biographical notes: Carlo Vezzoli is responsible of the Design and System Innovation for Sustainability (DIS) research unit inside the Design department (INDACO) of Politecnico di Milano University, and Professor of 'Design for environmental sustainability' and 'System design for sustainability' at Politecnico di Milano University. He coordinated several research projects and took part in EU funded researches. He currently coordinates a national network of universities for curricula development on design for sustainability (LeNS.Italia) and the EU funded research 'LeNS, the Learning Network on Sustainability'. He recently wrote: System Design for Sustainability, Maggioli, Design for Environmental Sustainability, Springer, and System Innovation for Sustainability, Greenleaf.

Fabrizio Ceschin works as a Researcher at the DIS research unit since 2006, dealing with innovation, design and development of products, services and systems targeting sustainable results. He is currently a $\mathrm{PhD}$ candidate in Design, working on the issue of 'design and radical changes for sustainability'. He took part in several research projects commissioned by companies and researches funded by EU. He is currently Project Manager of the EU funded 
research 'LeNS, the Learning Network on Sustainability'. He co-authored the book Method and Tools for Life Cycle Design. How to Design Low Environmental Impact Products, Maggioli Editore.

\section{Sustainable development and Design role}

It is widely shared that sustainable development requires a system discontinuity, meaning that radical changes in the way we produce and consume are needed.

In the second half of the '90s a series of studies and analyses led to a clearer understanding of the dimension of change necessary to achieve a society that is effectively and globally sustainable. It was then realised that conditions for sustainability can only be achieved by drastically reducing the consumption of environmental resources compared to the average consumption by mature industrialised contexts.

The debate about more sustainable consumption patterns has been included in the agenda of the major international governmental institutions over recent years starting with the United Nations. Particularly significant was the setting up of the Sustainable Consumption Unit of the UNEP (United Nation Environmental Programme) in May 2000. The initial assumption was that "in spite of the progress made by the industrial world and enterprise during the last decade $[. .$.$] the extent to which consumption exceeds$ the Earth's capacity to supply resources and absorb waste and emissions is still dramatically evident" (Geyer-Allely, 2002).

Some studies (taking into account demographic growth forecasts and hypothesising, rightly, an increase in the demand for well-being in currently disadvantaged contexts) have brought out a staggering result: conditions for sustainability are achievable only by increasing the eco-efficiency of the production-consumption system by at least ten times. In other words we can only consider sustainable those socio-technical systems whose use of environmental resources per unit of satisfaction/service is at least $90 \%$ less than what is currently done in mature industrial contexts (Jansen, 1993; Factor 10 Club, 1994; WBCSD, 1996).

These estimates are approximate and currently under scientific discussion. However, they are still valid to indicate the proportions of the change that should take place. A profound, radical transformation in our development model is necessary and the production and consumption system in this sustainable society will be profoundly different from what we have seen up to now.

The radical reduction of resources consumption and emissions in industrialized (and emerging) contexts, will require a shift from and idea of a society where well-being and economic health are measured in terms of growth in production and material consumption, to a society where people are able to live better consuming far less, and to develop the economy reducing the production of material products. At the same time the socio-ethical challenges will require a diffused increase of well-being in low-income (and emerging) contexts.

Given the nature and the dimension of this change, we have to see transition towards sustainability (and, in particular, towards sustainable ways of living) as a wide-reaching social learning process in which a system discontinuity is needed. Therefore a, system approach is important in order to seriously tackle the transition towards sustainability. 
Within this framework, what role for Design for Sustainability?

The following text synthetically describes how this discipline has enlarged its scope and field of action over time, as observed by various authors (Karlsson and Luttrop, 2006; Charter and Tischner, 2001; Vezzoli and Tamborrini, 2007).

A first level on which numerous theorists and academics have been working is the selection of resources (materials and energies) with low environmental impact. The focus was on the toxicity, harmfulness, recyclability, biodegradability and renewability of materials and energies.

Since the second half of the nineties, attention has partially moved to the product level, in particular to the design of products with low environmental impact, usually referred as product Life Cycle Design or Ecodesign or Design for Environment (Keoleian and Menerey, 1993; Brezet and van Hemel, 1997; Manzini and Vezzoli, 1998; Heskinen, 2002; Sun et al., 2003; ISO 14062, 2002; Nes and Cramer, 2006). In those years it became clear how to assess the environmental impacts related to a product, and how to design products with a lower environmental impact. In particular two main concepts were introduced. Firstly, the concept of life cycle thinking: it is not the single product to be designed (and environmentally assessed) but all the processes needed to produce the materials and components, assembly the product, distribute it, use it and finally dispose it. Secondly, the concept of functional thinking: it is not the single product to be designed (and environmentally assessed), but the function delivered by the product itself.

Over the last few years, starting with a more stringent interpretation of sustainability (that tells us that radical changes in the production and consumption system are needed), attention has partially moved to design for eco-efficient system innovation, therefore to a wider dimension than that of the single product (Stahel, 1997; Goedkoop et al., 1999; Brezet, 2001; Charter and Tischner, 2001; Manzini and Vezzoli, 2001; Zaring, 2001; UNEP, 2002). Within the wide debate on the definition of system innovation, design researchers have usually referred to the so called Product-Service System. Among the several converging definitions the one given by the United Nations Environment Programme (UNEP, 2002) says that a system innovation (referred to as Product-Service System, PSS) is "the result of an innovative strategy that shifts the centre of business from the design and sale of (physical) products alone, to the offer of products and services that are together able to satisfy a particular demand".

Still more recently, design research has opened discussion on a possible role of design for social equity and cohesion (Margolin, 2002; Mance, 2003; Manzini and Jegou, 2003; Rocchi, 2005; Penin, 2006; Tischner and Verkuij1, 2006). Hence, a potential role for a design directly addressing various aspects of social equity and cohesion, aiming at a "just society with respect for fundamental rights and cultural diversity that creates equal opportunities and combats discrimination in all its forms." (EU, 2006).

In synthesis, over the last few decades, the role of design has increased in relevance and recognition, enlarging its field of action from the selection of materials and energies, to the design of the product life cycle, to the design of eco-efficient system innovation, to the inclusion of socio-ethical aspects. Design for Sustainability (DfS) has been evolving in research, and design approaches, methods and tools are constantly developed and updated. DfS is in fact a relatively recent field, characterised by a constant and rapid advancement; but, because of this characteristic, on the other hand the problem is that there is still not a widespread dissemination of new research results. For these reasons, the key issue for researchers, teachers and students (in industrialised, emerging and low 
income contexts) is to find the most effective way to access to the most updated knowledge and advancements.

Within this perspective, what challenges for design Higher Education Institutions (HEIs)?

\section{Design HEIs challenges, and the LeNS project}

As highlighted in the previous section Design for Sustainability is a complex and relatively new (both academically and professionally) field of action, evolving at a continuous and rapid pace. For this reason it is clear that designers must have an updated theoretical background as well as an updated know-how that enable them towards a practice committed with the sustainability challenges. Consequently, design Higher Education Institutions (HEIs) and design researchers/educators, need to be able to equip design students with a broad knowledge base, as well as effective methods and tools so that a new generation of designers can play an active role within the transformation of our consumption and production patterns.

Under this perspective, there is a pressing need of "mechanisms" that act at the education level, enabling design educators, in industrialized, emerging and low-income contexts, to speed up the knowledge sharing in this field and come out with a design education agenda able to respond both to local and global sustainable development issues.

Within this scope it is operating the ongoing Learning Network on Sustainability (LeNS) project (2007-2010), an Asian-European multi-polar network for curricula development on Design for Sustainability (DfS) focused on Product-Service System innovation ${ }^{1}$, financed by the European Commission under the Asia-Links programme ${ }^{2}$. LeNS is an action of curriculum development in the field of Design for Sustainability and Product-Service System (PSS) innovation design. Its starting point is that a new generation of designers should be formed with the right conceptual and operative tools to be able to contribute to the transition towards a sustainable society. For that, design educators across regions should be able to create and incorporate new learning resources into existent or new curricula. In the LeNS project, the focus is on Europe and Asia, but its ambition is to reach worldwide design educators and HEIs through the production of outputs in a copy left ethos.

The main output of the project will be the so called Open Learning E-Package (OLEP), an open web platform that allows a decentralised and collaborative production and fruition of knowledge. It can be described as a modular e-package of teaching materials (slide shows, texts, audio, video, etc.) and tools for designers, that design researchers/educators (as well as students, designers, entrepreneurs and interested persons/institutions) worldwide will be able to download (free of charge), modify, remix and reuse (in a copy left logic).

Apart from the contents, the same OLEP platform is realised in an open-source and copy left logic, allowing its download and reconfiguration in relation to specific needs, areas of interest and themes.

In other words the LeNS project has the ambition of being a catalyser for actions and exchanges on education (and research) in design for sustainability worldwide, through the production of the previously mentioned open-source curriculum package (OLEP), and a replicable web-platform to be easily reproduced in a worldwide scale. 
In the following text the paper firstly presents the research process and approach adopted in the LeNS project. Secondly the paper discusses the potential opportunities and threats related to a free access, open-source and copy left learning model. Then the paper presents the achieved intermediate result: the Open Learning e-Package, describing its features and functionalities, and its implication for research, practice and society.

\section{LeNS process and approach}

The LeNS process foresees the development of new curricula reflecting both a shared macro agenda on sustainability and localised and contextual sustainability agendas (to respond to local needs and demands in the economic, social and cultural levels).

In synthesis LeNS partners firstly analyse what is their state of art in terms of didactic and research in DfS and PSS and express what are the main demands not yet covered. Partners then collect and develop new subsidies for new courses and come out with a first (beta) version of the Open learning e-package (OLEP). OLEP beta version is used (and tested) along 8 pilot courses at the partner institutions following an exchange modality: each partner hosts a guest teacher from another partner and each partner plays the role of guest teacher at another partner, according to an exchange agenda. The logic of this process is that of refining and expanding the beta OLEP along its implementation in the 8 pilot courses, feeding back the original pack. At the end of the pilot courses implementation, a "final" version of the OLEP is opened to external diffusion.

In particular the process can be described as follows (Penin and Vezzoli, 2008):

- 1 . State of the art. State of the art of current practices and experiences on DfS: each partner gathers and exchange their own knowledge, previous didactic and research experiences in the field and share specific priorities and approaches. This work is done according to the verification of DfS needs of each partner, in relation to their own sustainability agenda. The results represent the basis upon which the teaching modules are designed and teaching subsidies are developed.

- 2. Design of the didactic pilot modules and teaching subsidies. Development of all the necessary inputs for the implementation of the didactic pilot courses and teaching subsidies. Didactic pilot courses are designed and the necessary teaching subsidies are gathered or developed ex-novo (according to expressed needs and demands). The result is the first (beta) version of the OLEP (Open Learning E-Package), ready for testing. The beta version will be continuously updated along the implementation phase (3).

- 3. Implementation of pilot courses. The implementation of the didactic pilot module is carried out within a total period of 18 months. This time span allows in progress assessment of the teaching materials (OLEP) and consequent improvement for the remaining academic semesters. The didactic pilot courses are implemented in collaboration between the local teacher (host) and a guest teacher, in a transcultural learning/teaching process. It is foreseen that a third teacher (the observer) follows the pilot course implementation at the hosting schools reporting back the results of the OLEP development. 
- 4. Preparation of OLEP "final version". According to the results of the pilot courses implementation process, a "final" 2010 version of teaching subsidies is formalized. It is a final version regarding the LeNS project (that lasts three years: from December 2007 to December 2010). But, since it is an open package, it foresees its continuous updating and development, to be done by users after the termination of LeNS project. In fact at this point, the teaching package (OLEP) assumes an open-source model: an online platform for sharing learning objects on DfS, open to external users who will be able to use and transform the original material. In addition, the platform is thought to be reproducible i.e. using the original code, users can reproduce its architecture in a localized version, for example in different languages or focused on specific regions. During the whole process, an evaluation process is carried out in parallel, through both external evaluators and internal evaluators (the observers of the pilot courses). Dissemination activities are foreseen along the process and in the last phase to increase the diffusion of the in-progress and final results.

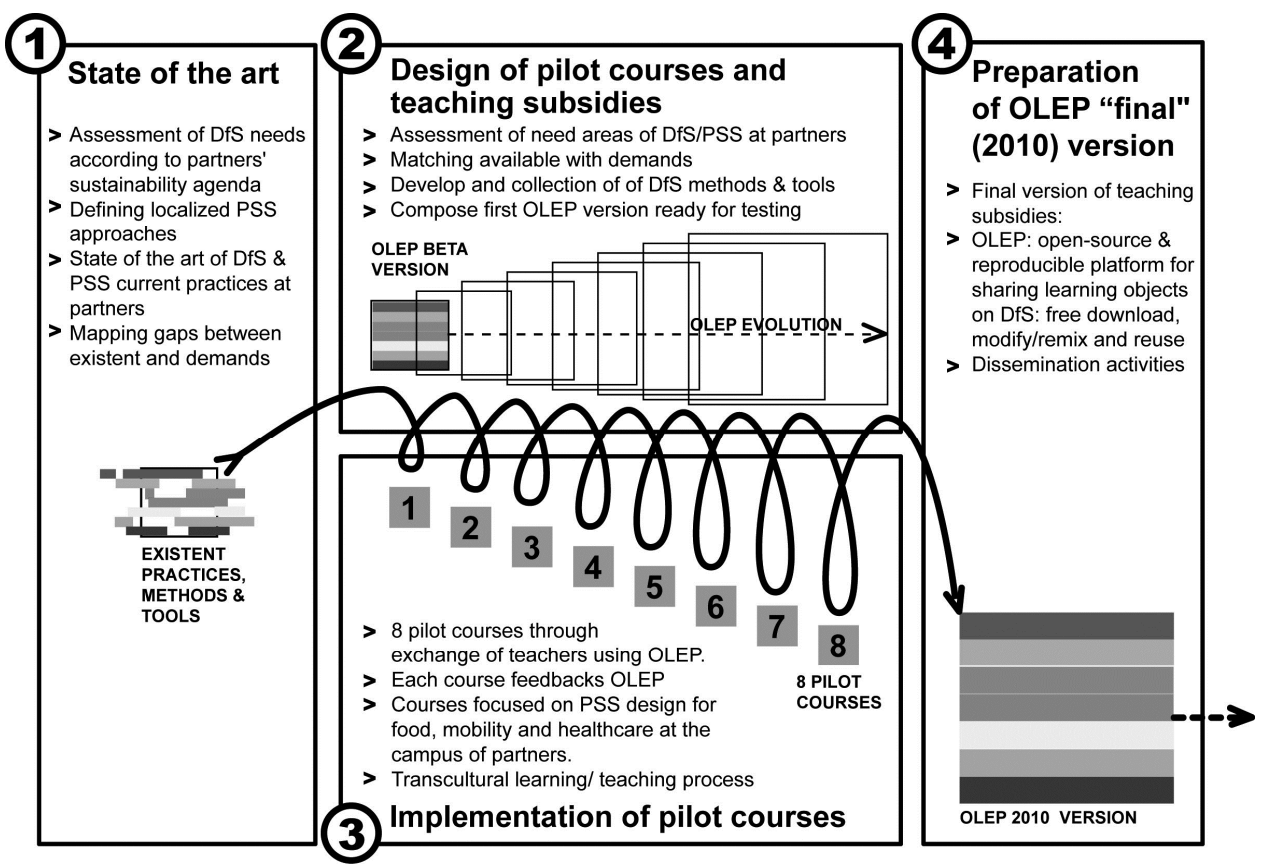

Figure 1 The LeNS learning process for the construction of the Open Learning E-Package.

LeNS project is currently undertaking the third phase. The OLEP beta version has been finalized, tested and improved in the first three pilot courses: "PSS design \& business" held at the Technical University of Delft in February 2009; "System Design for Sustainability" held at Politecnico di Milano in May 2009; "Product-Service System Design for Sustainability" held at IIT Delhi in July 2009. All the learning resources produced for these courses are available on the beta version of the OLEP platform, at www.lens.polimi.it. 


\section{The opportunities of a free-access, open-source, copy left and modular learning model...}

In the last ten years several web-platforms have been developed, by various organizations and universities, to promote and support an open source and open access educational and learning model (Materu, 2004).

Some of these web-platforms are only focused on favouring a free access to didactic contents. This is the case of several solutions implemented by various universities. For example the Massachusetts Institute of Technology's Open Course Ware ${ }^{3}$ (Baldi et Al. 2002), the Carnegie Mellon's Open Learning Initiative ${ }^{4}$, or the Open Course Ware Consortium $^{5}$ (developed in collaboration with more than 200 HEIs). Through these platforms it is possible to freely access and download course materials (texts, slide show presentation, and video recorded lectures) that reflect the undergraduate and graduate subjects taught in the related institutions.

In some other initiatives the focus is also on the development of learning objects following a specific standard. This is the approach adopted by the Centre for Excellence for the Design, Development and Use of Learning Objects ${ }^{6}$ (Bradley and Boyle, 2004; Boyle, 2006); in this case, instead of having didactic material in different and heterogeneous formats, in this web-platform it is possible to access learning objects characterised by being developed using the same multimedia format and standards. This characteristic facilitates the design, by other teachers, of specific learning paths (for example combining learning objects belonging to different courses).

In addition to allow an open access to learning contents, some other initiatives are also aimed at facilitating the reuse and adaptation of the same contents by other teachers and educators. Within this perspective the didactic material is specifically designed and built in a modular logic, in order to be easily re-adapted and re-assembled by other teachers in relation to specific learning needs. Examples of this approach are the Sharing Learning Objects in an Open Perspective ${ }^{7}$ project (Ravotto, 2007), and Connexions ${ }^{8}$ (Baraniuk et Al., 2004).

Some other web-platforms are aimed not only at allowing free access to learning contents, but also free access to teaching methods and modalities (see for example LeMill $^{9}$ (Toikkanen, 2008)). Educators can download didactic materials and even understand which are the best teaching modalities (in relation to the contents to be taught).

If in some of these web-platforms the upload of contents is restricted to specific persons (for example to professors or to the partners of a project consortium) in some other cases even the development and upload of learning contents is open to everybody (for example see the previously mentioned Connexions and LeMill). In other words these web-platforms are characterised not only by a free fruition of knowledge, but also by a collaborative production of knowledge.

Based on an analysis of the existing open-access and open-source web-platforms, the following text illustrates why a web-based, free-access, open-source, copy left and modular learning model can favour a more effective learning mechanism, potentially capable to tackle some of the problems related with the traditional methods of producing and transmitting educational information (within the field of Design for Sustainability). In the same way, in the $5^{\text {th }}$ section, the threats related to this kind of learning model are presented and discussed. 


\section{1 ...to facilitate knowledge dissemination}

A possible path to facilitate knowledge dissemination through teaching materials is that of making them free and available on-line. In this way it is enabled the less expensive option and the easiest access, since users can use teaching materials on-line at no-charge, or download and print them (in toto or only the needed parts). Moreover geographic location is no longer a barrier for having access to research results and teaching materials.

The matter of access to knowledge becomes even more crucial in a research field like Design for Sustainability, characterised by being quite recent and therefore not extensively disseminated. This is moreover an area in which the knowledge evolves at a rapid pace, and therefore an on-line free access can potentially allow rapid dissemination of updated knowledge, with obvious positive effects on teaching, learning and research.

\section{2 ...to facilitate continuous and rapid knowledge upgrade}

Knowledge is in a constant advancement: new ideas, concept and theories are introduced; existing information is reviewed and refined, while outdated information is removed. The traditional process by which this takes places includes the publication in books and refereed journals: research results are submitted to publishers, pass through a peer-review process for an independent verification, and finally are published. This is an important process to guarantee the scientific reliability of what is published, nevertheless it could result inefficient where knowledge evolves at a rapid pace. In other words for rapidly changing knowledge the traditional process of transmitting research results could be supported by other innovative ways of knowledge sharing. Researchers and teachers (and students), should have complementary ways to access to the most updated knowledge and discoveries in their respective fields.

To reduce this gap of time some researchers have increasingly adopted, through the use of internet technologies, informal exchanges of knowledge with their reference scientific communities. In online environments, colleagues can share knowledge freely, allowing works to be annotated, discussed, reworked and rapidly republished (Henry, 2004). For these reasons, an on-line platform through which share knowledge can potentially increase dissemination of new ideas and research results, thus facilitating a readily access, review and update of information. Moreover this fresh shared knowledge stimulates innovation, since researchers can immediately start from it to build on. In addition, even students will benefits from this kind of transmitting of knowledge, since teaching materials can be constantly reviewed and updated.

\section{3 ...to facilitate collaboration between researchers/teachers}

As it has been just underlined, in research fields quite recent and in rapid development, like Design for Sustainability, it is of key importance that researchers/teachers work with each other across institutions and geographic boundaries in order to increase a focused share of knowledge and experience. This allows research results to be readily discussed, refined and translated into teaching materials. In this way colleagues of a same scientific community can collaborate directly with each other, modifying and integrating contributions produced and edited by others, and therefore keeping the knowledge up to date; reuse of knowledge is encouraged and new ideas can readily evolve (Baraniuk et Al., 2004). In this sense an online web platform through which stimulating collaboration 
between researchers/teachers can potentially foster the advancement of knowledge and therefore foster the realization and delivery of higher quality courses (Björk, 2001).

\section{4 ...to facilitate knowledge adaptation in relation to different students (learners)}

Different students (learners) are differently able to absorb information. In fact they may have different learning approaches, and therefore a fixed and static teaching material may result appropriate for some students and not for others. If a learning resource (whether a text a slideshow or other) results difficult to understand for a given group of students, their teacher may intervene on the material, modifying it or delivering it in an alternative way.

In order to facilitate the adaptation of knowledge information to different students' (learners') characteristics, knowledge could be transmitted in a modular and open-source modality. In this way teachers could potentially be able to easily modify/integrate the different modules, and to remix them to respond to the need of different learners' needs. Moreover, if this process of modules adaptation and remix is shared through a webplatform, it could also facilitate and stimulate other teachers in doing the same operation.

\section{5 ...to facilitate knowledge adaptation in relation to different contexts}

In research fields like Design for Sustainability, in which the vision and the approach to be adopted vary in relation to the context characteristics, it is important to find innovative sharing mechanism. In fact knowledge and the way in which it is delivered to learners have to take in consideration the great diversity of each context (in terms of economic, social and cultural characteristics). Going in the specific of Design for Sustainability, it has to be ensured that the development and delivery of teaching materials reflect both a shared macro agenda on sustainability, but also localised, contextual sustainability agendas that respond to local needs and demands in the economic, social and cultural levels.

For these reasons a knowledge transmitted in a modular and open-source modality (but also organized in courses in order to answer to the different teachers' necessitates and starting conditions, i.e. new course activation or course upgrade), could fit the previous mentioned needs, enabling easy adaptation by teachers in relation to specific local needs and context characteristics. Moreover, if this process is shared through a webplatform, it could also facilitate and stimulate teachers operating in similar contexts to share experiences and teaching materials.

\section{6 ...to foster high quality courses}

As we have seen, if knowledge is transmitted trough a web-based, free-access, opensource and modular logic, the advantages are in terms of continual refinement of modules and courses (because teachers can make use of updated information and knowledge), and possibility of adaptation to learners' needs and context specific characteristics. An obvious result is that modules and courses can potentially be delivered with a higher quality. The possibility of continual refinement and adaptation of teaching materials is even more important in recent research fields like Design for Sustainability, in which the research results have to be translated "just-in-time" in teaching materials. In this situation 
it becomes of crucial importance the possibility of having a virtual space in which researchers/teachers may continuously share experience and up to date knowledge, and in this way improve their teaching materials.

\section{The threats of a free-access, open-source, copy left and modular learning model...}

The production and sharing of knowledge in an open logic is not only linked with potential benefits and opportunities, but also with potential threats and problems. The main problem is in fact the control of the scientific reliability of the produced contents (Materu, 2004). In addition there is also the issue of knowledge dispersion when open platforms accept any kind of content (not focused to specific themes), targeted to any kind of user.

\section{1 ...to appoint the scientific reliability of teaching materials}

If the upload of teaching materials in a web-platform is open to everybody, it is quite clear that there is a problem related to the scientific reliability of the available contents. In order to tackle this weakness a possible answer could be to establish a scientific board, to guarantee the scientific quality of the uploaded contents. In addition, or as an alternative, the possibility of uploading materials could be restricted to specific institutions/teachers.

Both of the approaches have been adopted by LeNS. In this sense a scientific board, made up of one member from each project partner, has been set up with the aim of controlling the scientific quality of the produced materials. Furthermore an external evaluator team (made up by key worldwide experts on the field of Design for Sustainability) has been appointed by LeNS partners in order to control the scientific reliability of the uploaded learning resources. In addition, in order to facilitate this process, it has been decided that only the partners have the possibility to upload learning contents on the web-platform. In addition, partners' teachers have the opportunity to allow (after a review and on their responsibility) other teachers to contribute in the OLEP contents development. This process of scientific reliability control (with the exception of the external evaluator team) will be preserved after the formal conclusion of the project.

If this solution is capable to safeguard and guarantee the scientific reliability of the uploaded learning resources, it is also true that on the other hand the process of enrichment and enlargement of teaching materials is hindered; opportunities to increase the quantity of available didactic materials are strongly reduced. For this reason it has been imaged (as it will better illustrate in section 7) that the same web-platform can be downloaded and re-adapted; any educational institution/teacher can in fact "generate" a new LeNS-based web-platform, reconfiguring it by re-defining partners, the scientific board, the specific themes (that have to be linked with sustainability and design), and the geographical representation. Members of new "replicated" LeNS platforms will be responsible of the scientific reliability of the uploaded contents.

\section{2 ...to address the scientific community}

If knowledge platforms are open to different and not linked topics (for example from arts to engineering to history, etc.) they run the risk to become dispersive and, as result, not to 
address in a effective way the scientific community. In order to tackle this potential problem an open web-platform should focus on specific and targeted topics, as in the case of LeNS, which develops learning resources targeting Design for Sustainability issues.

\section{LeNS main result: the Open Learning E-Package (OLEP)}

In the previous sections we have seen the main opportunities and threats linked to an educational model based on a collaborative production and fruition of knowledge. In the following text we will enter in the details of the Open Learning E-Package (OLEP): the main result of the LeNS project. As said before the OLEP can be described as an epackage composed of a set of modular learning resources targeted at design educators, to facilitate the activation and implementation of courses on Design for Sustainability (DfS) with a focus on sustainable Product Service Systems innovations. The learning resources of the OLEP will be easily to be used and free, being based on an open-source and copy left logic: teachers (as first intermediate learners) can download, modify and reuse the available set of learning resources. The OLEP is obviously targeted even at students, and other professionals for their continuous education such as designers, entrepreneurs and interested persons/institutions. The OLEP will be located within the LeNS web platform (www.lens.polimi.it). The following text will focus on the technical details of the OLEP.

\subsection{Generation and acquisition of contents}

The open learning e-package contents are produced during the LeNS project by the partners' teachers, but can incorporate other existent or future materials considered as interesting and relevant. Most part of the materials will be developed prior to the pilot course implementation and will evolve in synergy with the courses implementation (see figure 1). It will be edited into its final shape after the pilots' implementation.

The teaching materials will be developed based upon the identified needs. They will be also partly based upon the teaching materials of the partner institutions developed prior to the LeNS project, as well as new teaching materials to be developed ex-novo. Each topic will be covered by a range of different supporting media. These activities will be concentrated before the beginning of the first pilot course, but will continue along the whole implementation process, that is spread in an 18 months time span.

Next to the teaching materials developed and collected in the preparatory phase, the core of the OLEP will be constituted by the materials used in (selected to/developed for) the 8 pilot courses. In practice, in each pilot course it will be developed: a programme for the course; a series of slideshow presentations to support the lecture; a series of related video-recorded lectures.

Each partner preparing a new pilot course will use the OLEP so far produced, and so will make use of what has been produced in the previously courses. After the implementation of each of the 8 pilot courses, an evaluation will be carried out (based on the observers report) to assess the impact of each of the teaching materials used. This assessment will inform the teachers of the next pilot courses as well as the progressive development of the OLEP final version (indicating for example if a given learning resource needs to be adjusted, materials that work better in a given context, etc). 


\subsection{OLEP general requirements}

In practice, the open learning e-package contents will be:

- Indications, guide-lines and examples of courses (programmes, supporting materials, expected results, etc) targeting teachers who wish to activate new courses or renew existing ones on system design for sustainability (incorporating it on the school/university curricula)

- Materials (slideshow; slideshow + video recorded lecture; slideshow + audio recorded lecture; video; text; or other formats), and tools to support teachers in holding courses and didactic modules, on system design for sustainability.

- Materials (slideshow; slideshow + video recorded lecture; slideshow + audio recorded lecture; video; text; or other formats), and tools to support students who follow courses on system design for sustainability.

- Materials and tools to support designers in incorporating DfS thinking into their practices.

The OLEP is meant as a modular package of learning modular resources. Any interested design teacher is allowed to: download, modify/remix and reuse. The aim is to allow any design teacher to adapt and use the learning resources he/she finds useful, according to his/her specific didactic needs, institutional requirements or local context particularities. Also students and designers are welcomed to access the OLEP to support their learning activities (linked or not to a given course).

The OELP contents will take different formats: texts in different formats, such as print-on-demand from the publisher (with ISBN code), printable in common printers (whole or partially), readable on screen, editable files (for open-sources documents, modifiable by the user); slideshow presentations; composed presentations that integrate video-recorded lectures (teachers classes and students presentations) with slideshow presentations; audio or audio/video files (e.g. recorded lectures); software and other tools; archives and databases of best practices, examples, etc.

All e-package contents are characterised by: being downloadable for free (freeaccess); having a modular structure; being developed with an open-source and copy left logic, with intellectual property rights (authorship), but without restrictions to diffusion (i.e. Creative Commons license).

\subsection{OLEP functionalities}

Learning resources can be accessed as single objects or grouped objects (as related to a particular course/teacher).

More precisely two modalities of access have been so far identified: 1 . access to all learning resources of a particular course/teacher; and 2. access by content to single learning resources (regardless the teacher/course).

In relation to the upload of learning resources, two modalities have been defined: 1 . upload/modify learning resources related to a particular course (learning collection); 2. upload/modify single learning resources. 


\subsubsection{DOWNLOAD/VIEW - Access to all learning resources of a particular courselteacher}

Users can search for a particular course (fig. 2), visualize its structure and organization and get access (visualisation and download) to all the learning resources (fig. 3).

This functionality is especially thought for:

- teachers who want to start a course on DfS focused on PSS from the beginning and thus could be interested in an overview of the organisation of all the contents within a course, and searching for appropriate learning resources to download, modify, integrate and reuse;

- $\quad$ students who want to receive support for the course they are following, could have all the related learning resources gathered.

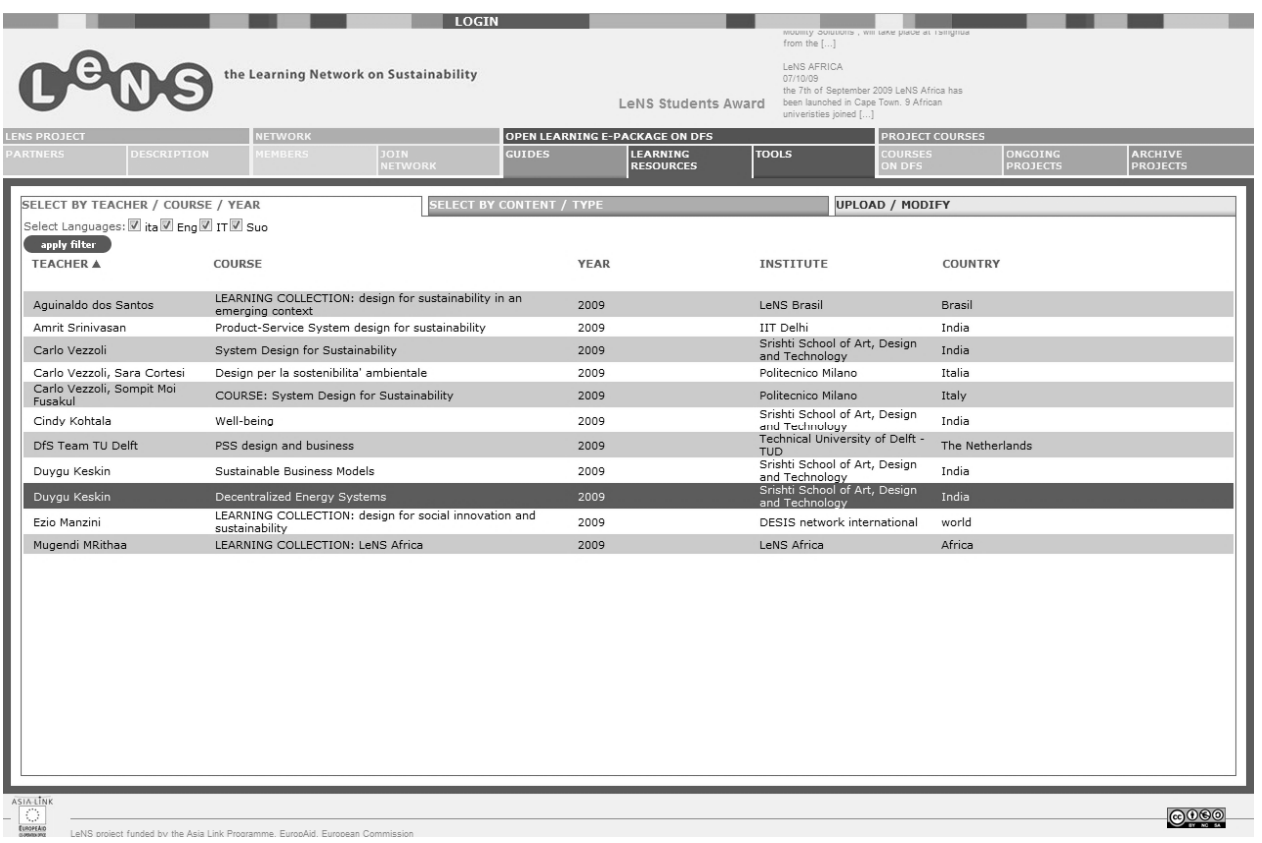

Figure 2 SELECT BY COURSE/TEACHER - User selects the desired language and gets access to a list of courses; these courses can be ordered by teacher, course name, learning hours, year, institution and country; user selects the desired course and gets access (fig. 3 ) to its organization and contents. 


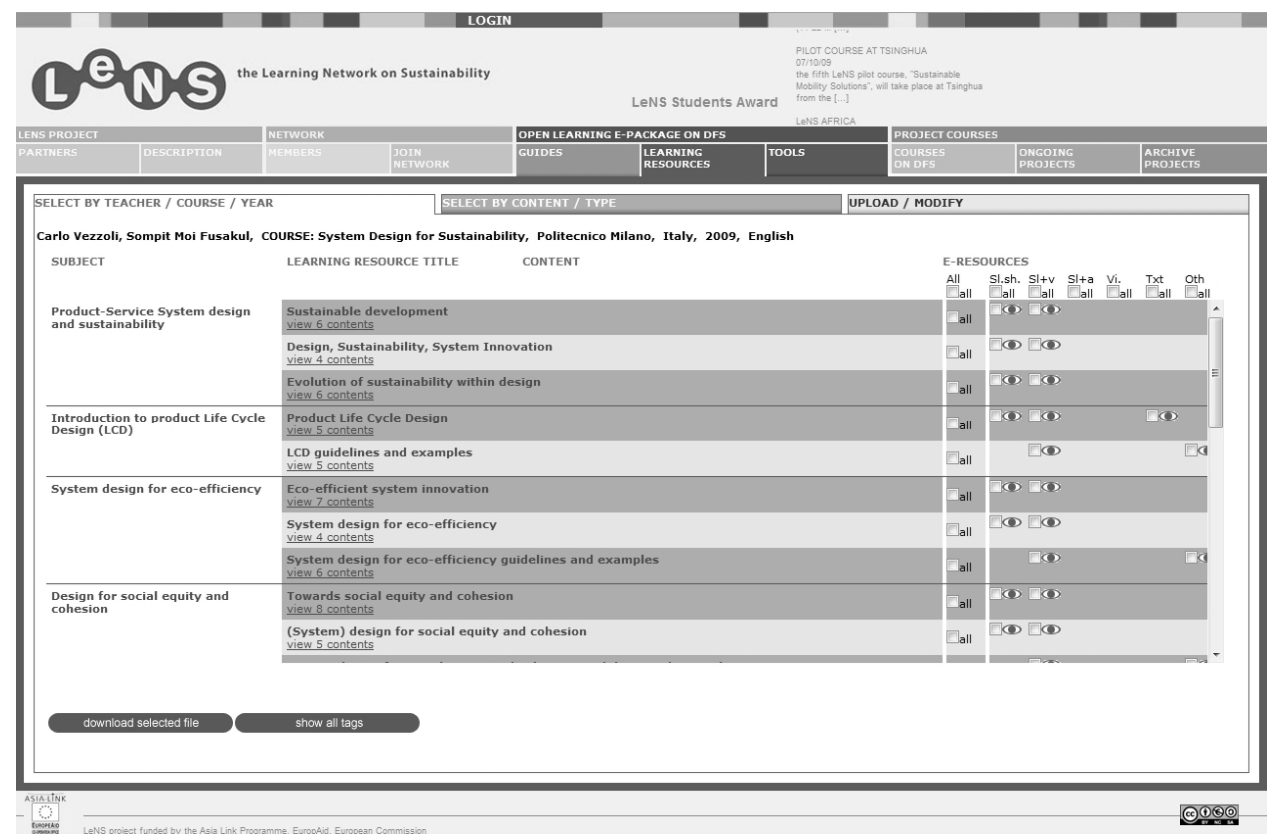

Figure 3 SELECT BY COURSE/TEACHER - User visualises the structure of the course: which are the Learning Subjects (LS) and which are the Learning Resource (LR) titles grouped under each LS. For each LR titles (which are described by a set of contents), it is possible to see which are the LRs uploaded. These LRs are ordered in relation to the type of format (slideshow, slideshow+video, slideshow+audio, video, text, or other). It is possible to visualise them (clicking on the "eye" icon), or download the selected ones.

\subsubsection{DOWNLOAD/VIEW - Access by contents to single learning resources}

Users can search for particular learning resources through a research by contents (fig. 4), and get access (visualisation and download) to all the related learning resources (fig. 5).

This functionality is especially thought for:

- teachers who wants to improve a course on DfS and thus can get direct access to all the materials that has been produced/collected related to a specific issue.

- $\quad$ students who wants to deepen a certain issue/theme and thus can get direct access to all the materials related to it, independently from teacher's indications. 


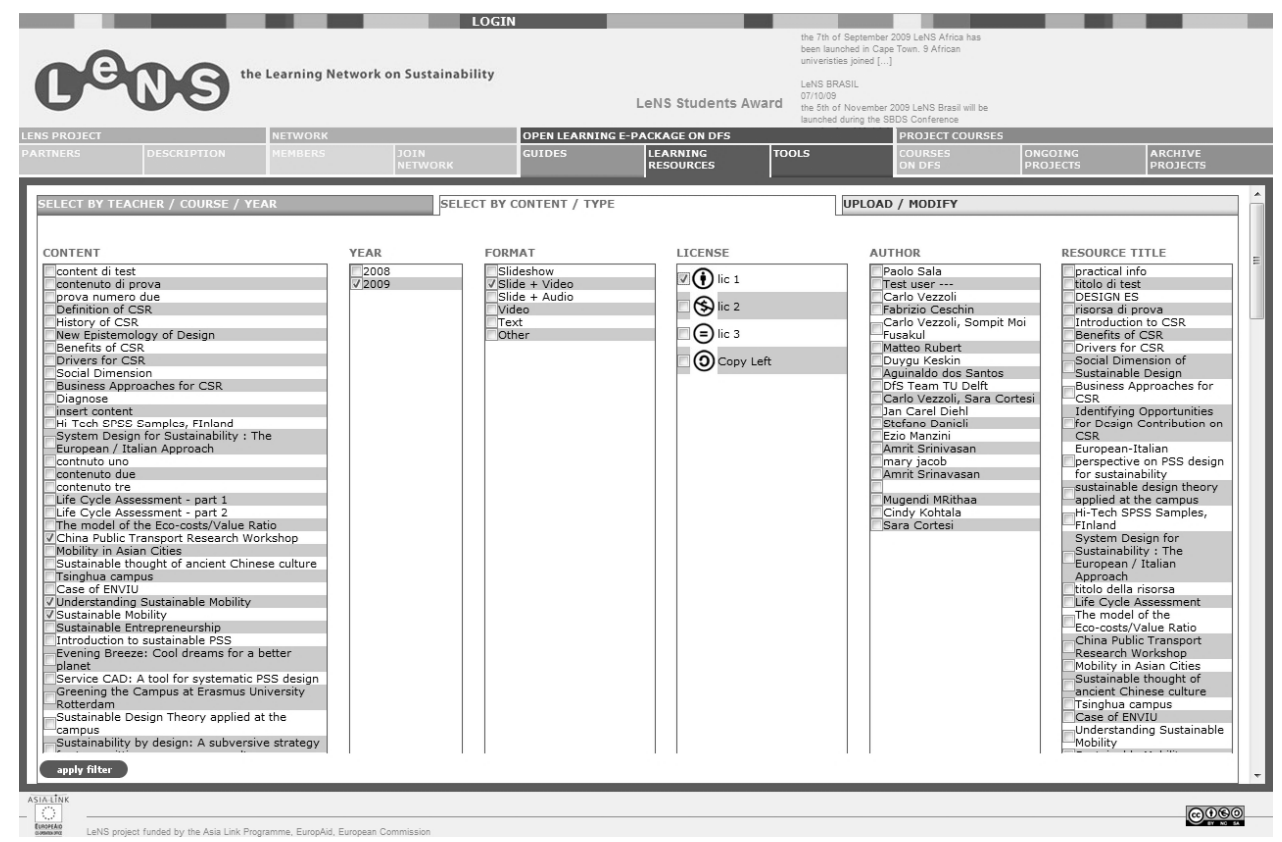

Figure 4 SELECT BY CONTENT - In the first five columns user can search respectively by content, year, type of license, and author; the column in which user operates works as filter for the others (e.g. if you click on a specific author you will see only the contents associated to him/her). The last column visualises the result of the research: a list of Learning Resources. At this point user can select the LRs he/she wants to visualise, and click on "view/download".

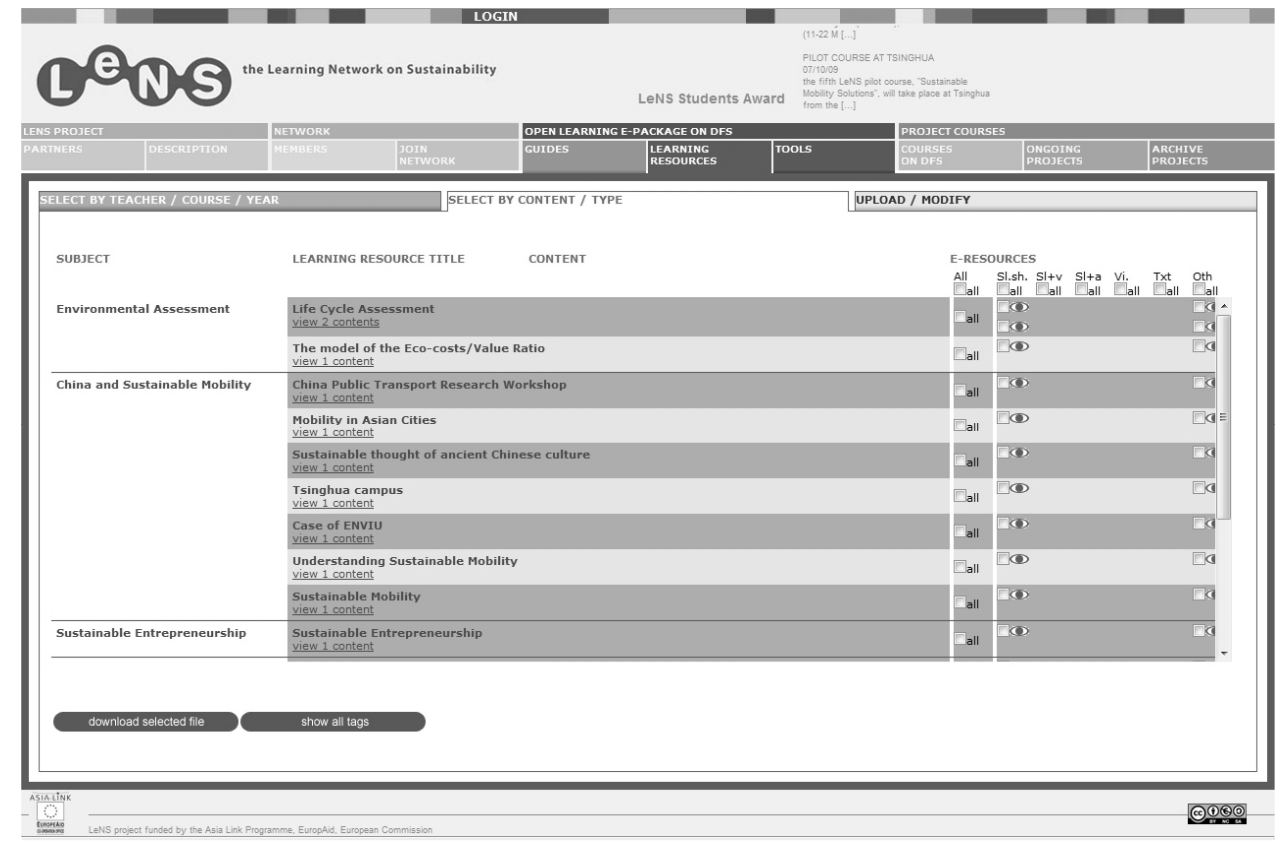


Figure 5 SELECT BY CONTENT - User can visualise, for each content previously selected, the related Learning Resource (LR) titles. For each LR title it is possible to see a set of information (which are the associated contents, author/s, realization year, and type of license), and the uploaded LRs. These LRs are ordered in relation to the type of format (slideshow, slideshow+video, slideshow+audio, video, text, or other). It is possible to visualise them (clicking on the "eye" icon), or download the selected ones.

\subsubsection{UPLOAD/MODIFY - Upload/modify learning resources related to a particular course/learning collection}

Teachers who are part of the LeNS consortium will be able to update the e-package during and after the project. They represent the OLEP scientific board, which will control the e-package updating, safeguarding the scientific reliability of the new materials. External teachers and users of OLEP will be enabled in uploading learning resources only if the scientific board allow them.

To upload a new course (learning collection), user enters in the "upload/modify" area (fig. 6), sets up the structure of the course (defining the Learning subjects and related Learning Resource titles), and, within each LR title, uploads the related LRs (fig. 7).

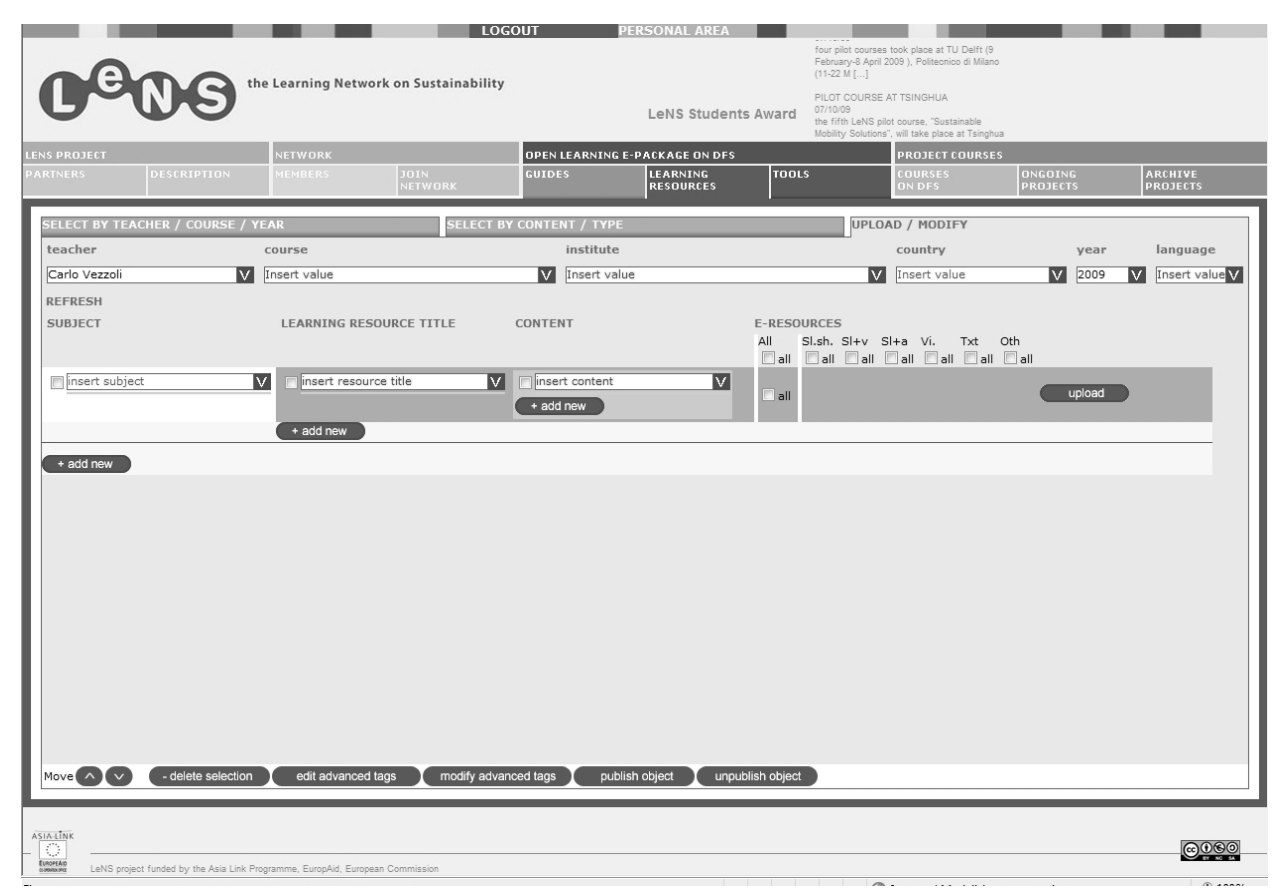

Figure 6 UPLOAD/MODIFY - After entering the "upload/modify" section, user can see in the upper part of the interface all the information related to his/her course; some of these information are automatically assigned by the system (but can be changed), while some others have to be inserted by the user (e.g. course name). Below these information there are 4 main columns: subject, learning resource title, content, and e-resources. User can operate in this area building up the structure of his/her course: he can add subjects, and under each of them add the related LR titles. 


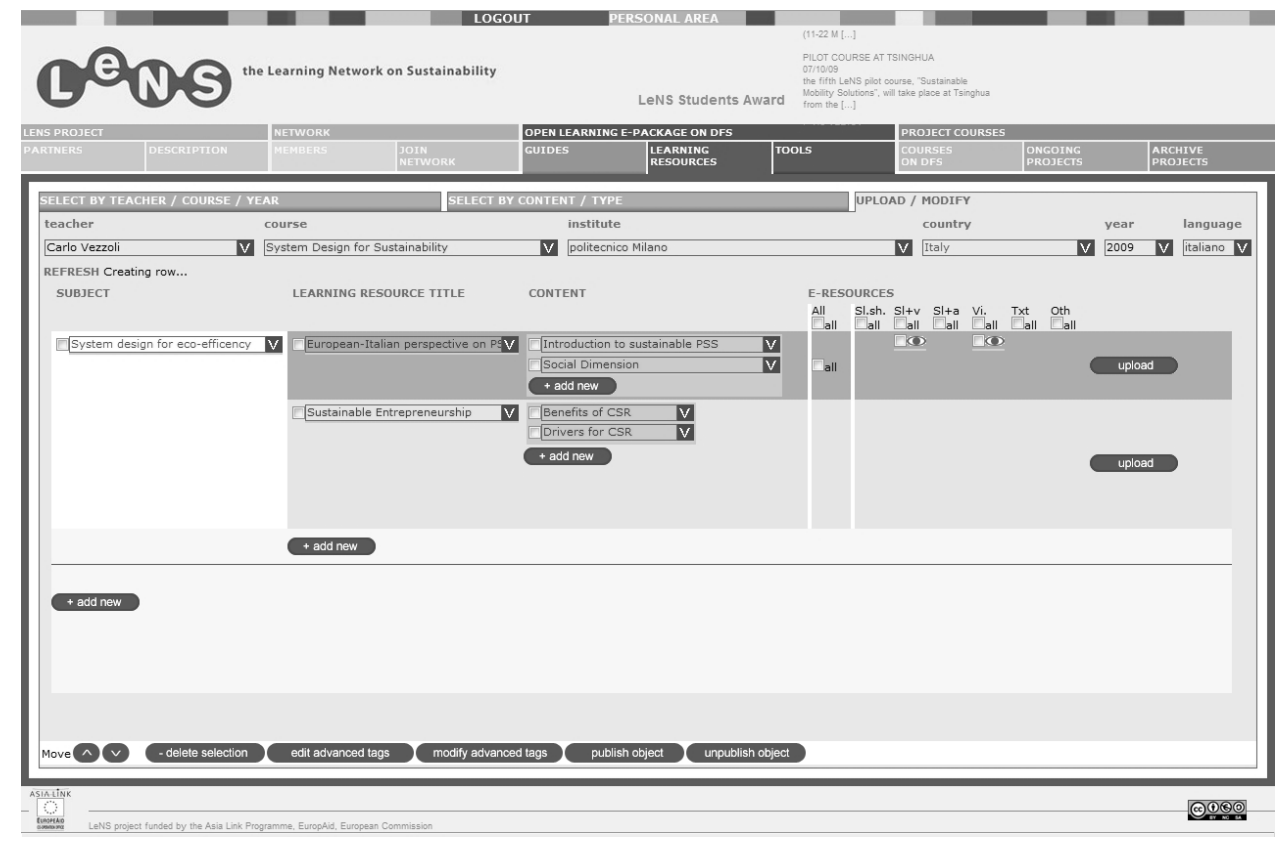

Figure 7 UPLOAD/MODIFY - User builds up the course structure and for each Learning Resource title uploads the related Learning Resources. LR are ordered in the last column in relation to the type of format: slideshow, slideshow+video, slideshow+audio, video, text, or other. During these operations he/she can: modify the order of the LS and LR title, delete LS and LR titles, add/modify LRs metadata. After that he/she can publish the course, to make it visible and downloadable.

As said before users have also the possibility to upload single learning resources; in this case the procedure is similar to the one that has been just described.

\section{LeNS as a replicable web-platform}

As said before a free-access, open-source, copy left and modular learning model, is characterised by presenting opportunities (it facilitates: knowledge dissemination, knowledge upgrade; knowledge adaptation in relation to different contexts/learners; collaboration between researchers and teachers), but also threats (problems related to the scientific reliability and the dispersion of knowledge). LeNS approach has been targeted at safeguarding opportunities and at the same time reducing/avoiding threats. For this reason it has been decided to develop a regenerative, "replicable" web platform (see also section 5). In other words not only the contents, but the same LeNS web-platform is downloadable as open-source and copy left artefact:

- $\quad$ any educational institution, teacher, sustainability-focused network, can generate a new LeNS-based web-platform, reconfiguring it by re-defining partners (the scientific board), the sustainability focus, the geographical representation;

- $\quad$ any new generated web-platform will upload and manage learning resources independently (controlling also the scientific reliability); 
- $\quad$ any new generated web-platform will be linked to the others.

In other words the LeNS web-platform is intended as a true open source artefact. It is realised in an open-source and copy left logic, allowing its download and reconfiguration in relation to specific needs, area of interest and geographic representation.

A proliferation of locally/content-based interconnected networks of design communities is in this way supported (and promoted). Within this perspective we see the launch, in September 2009, of LeNS Africa ${ }^{10}$ (Vezzoli, Ceschin and M'Rithaa, 2009), and the launch, in November 2009, of LeNS South America ${ }^{11}$ (other launches are under definition, e.g. in the United Kingdom and in Japan).

Each of this affiliated networks will be linked with each other in a multi-polar structure, so forth being at the same time independent and focused on specific needs and themes (for example the South American network will focus on design for sustainability in emerging contexts). In relation to the scientific reliability of the uploaded materials, each "affiliated" network will be responsible of controlling the scientific quality of what will be produced.

\section{LeNS project and its implications for research, education, practice and society}

LeNS aims at becoming a mechanism for the development and diffusion of system design for sustainability in design universities and schools. It appears to us that this is proposed in the right moment, when sustainability is being incorporated in the worldwide agenda, and in all levels there is a clear perceived growing demand of design for sustainability. It appears also that it is the right opportunity, of interfering at the education level, since education is very much the base of every change.

Within this framework LeNS ambitions to offer an open output, a free-access, opensource, and modular-content web-platform for storing and sharing knowledge (learning resources in design for sustainability, courses, guide-lines and examples, teaching materials, methods, tools, presented through different supports texts, slide presentations, video, audio, etc) among design educators, students and practitioners. It is intended also as a reproducible platform, allowing interested users to reproduce its architecture in localized versions, in different languages or focused on specific regions or themes.

In other words the LeNS web-platform is characterised by being open (because its contents are freely available for teachers, students, designer, companies and interested persons), multi-polar (because teachers from all over the world can contribute to the contents development bringing their own inputs and perspectives), interconnected (because there is a continuous exchange and sharing of contents and didactic materials), and regenerative (because the same web-platform can be downloaded and reconfigured in relation to specific needs).

Within this perspective, which are the LeNS project implications for research, education, practice and society?

LeNS allows a process of mutual learning, facilitating a readily access, exchange, review and update of knowledge. In this sense LeNS is intended as a sort of crosslearning mechanism among design researchers and educators, in which each of them can learn from each other. For this reason LeNS can potentially speed up the achievement of research results on the one hand, and their dissemination on the other. 
If research results are readily disseminated and shared between researchers and teachers, it is clear that, as a consequence, there could be an improvement in the quality of education. In fact, through the LeNS web-platform, research results can be translated "just-in-time" in teaching materials freely available all over the world. Moreover it has to be underlined that LeNS not only allows sharing teaching contents, but also teaching views and approaches. In this way design educators can learn from each other also in terms of teaching modalities.

An improvement in the quality of education will of course benefits design students, which can be formed with the right conceptual and operative tools to be able to design sustainable products, services and system organisations. And today's students will be the designers of the future. In this sense design consultancies and company design departments will benefit from better-qualified design graduates. In other words LeNS project will potentially bring improvements, in the medium/long term, also to design practice.

For this reason in the long term there could be a contribution in creating and disseminating innovative and sustainable solutions. In particular the dissemination of sustainable Product-Service System (PSS) concept offers a great potential as a promising entrepreneurial model potentially capable to facilitate the process of socio-economical sustainable development (see section 1). In this sense LeNS, fostering a new generation of design researchers and educators, aims at promoting a new generation of designers effectively capable to have a role as catalysers and enablers of the transformation of our consumption and production patterns, with consequent positive implications for the whole society.

\section{Acknowledgements}

The paper is the result of the collaboration between the two authors; nevertheless Vezzoli wrote sections 1, 3, 5, 6.1, 6.2 and 7; Ceschin wrote sections 2, 4, 6.3 and 8 .

\section{References}

Baldi, S., Heier, H., and Stanzick, F. (2002) 'Open courseware vs. open source software - a critical comparison', paper presented at the "Xth European Conference on Information Systems", Gdańsk, Poland, June 6-8, 2002.

Baraniuk, R. G., Henry G., and Hendricks B. (2004) 'Peer to peer collaboration with Connexions', paper presented at EDUCAUSE 2004 Annual Conference, Denver, Colorado, October 2004. (online at: http://cnx.org/aboutus/publications).

Björk, B.C. (2001) 'Open Source, Open Science, OpenCourseWare', proceedings ECAADE Education for Computer Aided Architectural Design in Europe, Helsinki, Finland, August 29 31, 2001. Online: http://www.hut.fi/events/ecaade/E2001presentations/01_01_bjork.pdf.

Boyle, P. (2006) 'The design and development of second generation learning objects', paper presented at the "Ed Media 2006, World Conference on Educational Multimedia, Hypermedia \& Telecommunications", Orlando, Florida, June 28, 2006.

Bradley, C., and Boyle, T. (2004) 'The design, development and use of multimedia learning objects', Journal of Educational Multimedia and Hypermedia, Special Edition on Learning Objects, Vol. 13, No. 4, pp.371-389.

Brezet, H., and van Hemel, C. (1997) Ecodesign. A promising approach to sustainable production and consumption, Paris: UNEP. 
Brezet, H., Bijma, A.S., Ehrenfeld, J. and Silvester, S. (2001) The design of eco-efficent services. Methods, tools and review of the case study based "Designing eco-efficent Services" project, report by VROM, The Hauge.

Campi, A., Colorni, A., and Giorgietta, M. (2007) 'Learning object meta-data (LOM) in SLOOP', in Ravotto, P. (Eds): SLOOP Sharing Learning Objects in an Open Perspective, Milan, ITSOS Marie Curie.

Charter, M., and Tischner, U. (2001) Sustainable Solutions. Developing Product and Services for the Future, Sheffield, Greenleaf publishing.

Colorni, A. (Eds) (2006) KIWI Knowledge Interaction Web Information, Milan, Centro Metid Politecnico di Milano.

European Union (EU) (2006) Renewed Sustainable development strategy, Council of the European Union, No. 10117/06, Brussels, 2006.

Factor 10 Club (1994) 'Declaration of the Factor 10 Club', available at: http://www.factor10institute.org/files/factor_10_club/F10Club-Statement_1994_e.doc

Geyer-Allely, E. (2002) 'Sustainable consumption: an insurmountable challenge', in UNEP, Industry and Environment Review. Paris: UNEP.

Goedkoop, M.J., van Halen, C.J.G., te Riele, H.R.M. and Rommens, P.J.M. (1999) Product Service Systems, Ecological and Economic Basis, PricewaterhouseCoopers N.V./Pi!MC, Storrm C.S., Preconsultants.

Henry, G. (2004) 'Connexions: an alternative approach to publishing', paper presented at ECDL 2004 European Conference on Digital Library, University of Bath, United Kingdom, September 2004, available at: http://cnx.org/aboutus/publications/Connexions-alt-pubcolor.pdf/).

Heskinen, E. (2002) 'The institutional logic of life cycle thinking', Journal of Cleaner Production, Vol. 10, No. 5.

ISO 14062 (2002) Environmental Management - Integrating Environmental Aspects into Product Design and Development, ISO/TR 14062:2002(E), Geneve: ISO.

Karlsson, R., and Luttrop, C. (2006) 'EcoDesign: what is happening? An overview of the subject area of Eco Design', Journal of Cleaner Production, Vol. 14, No. 15-16, Elsevier.

Keoleian, G. A., and Menerey, D. (1993) Life cycle design guidance manual. Environmental requirements and the product system, USA, EPA.

Jansen, J. L. A. (1993) Towards a sustainable Oikos, en Route with Technology!: CLTM.

Mance, E. (2003) La rivoluzione delle reti. L'economia solidale per un'altra globalizzazione, Bologna, EMI.

Manzini, E., and Jegou, F. (2003) Sustainable everyday. Scenarios of Urban Life, Milan, Edizioni Ambiente.

Manzini, E., and Vezzoli, C. (1998) Lo sviluppo di prodotti sostenibili, Rimini, Maggioli Editore.

Manzini, E., and Vezzoli, C. (2001) 'Strategic design for sustainability', in TSPD proceedings, Amsterdam.

Margolin, V. (2002) The Politics of the artificial, Chicago, University of Chicago press.

Materu, P. (2004) 'Open source courseware: a baseline study', available at: http:// siteresources.worldbank.org /INTAFRREGTOPTEIA/Resources/open_source_courseware.pdf

Nes van N., Cramer, J. (2006) 'Product Life time optimization: a challenging strategy towards more sustainable consumption patterns', Journal of Cleaner Production, Vol. 14, No. 15-16, Elsevier.

Penin, L. (2006) Strategic design for social sustainability in emerging contexts, PhD thesis, Milan, Poliecnico di Milano.

Penin, L., and Vezzoli, C. (2008) 'The Learning Network on Sustainability. A mechanism for the development and diffusion of system design for sustainability in design schools', in Cipolla C., and Peruccio P.P. (Eds.): Changing the change. Design, visions, proposals and tools. 
Torino, Umberto Allemandi \& C. Proceedings of the "Changing the change" conference, Turin, Italy, 10-12 July 2008.

Ravotto, P. (Eds.) (2007) SLOOP Sharing Learning Objects in an Open Perspective, Milan, ITSOS Marie Curie.

Rocchi, S. (2005) Enhancing Sustainable Innovation by Design. An approach to the Co-creation of Economic, Social and Environmental Value, PhD Thesis, Rotterdam, Erasmus University.

Stahel, R. W. (1997) 'The Functional Economy: Cultural Change and Organizational Change', in Richards D.J. (Eds.): The Industrial Green Game, Washington, National Academic Press.

Sun, J., Han, B., Ekwaro-Osire, S., and Zhang, H. C. (2003) 'Design for Environment: Methodologies, tools, and implementation', Journal of Integrated design and process science, Vol. 7, No. 1, pp.59-75.

Tischner, U., and Verkuijl, M. (2006) Design for (social) sustainability and radical change, paper presented at the "Perspectives on Radical Changes to Sustainable Consumption and Production" conference, Copenhagen.

Toikkanen, T. (2008) 'Simplicity and design as key success factors of the OER repository LeMill'. eLearning Papers, $\mathrm{N}^{\mathrm{o}}$ 10, September 2008, ISSN 1887-1542.

United Nations Environmental Programme, UNEP (2002) Product-Service Systems and Sustainability. Opportunities for sustainable solutions, Paris, UNEP.

Vezzoli, C. (2007) System design for sustainability. Theory, methods and tools for a sustainable "satisfaction-system" design, Rimini, Maggioli Editore.

Vezzoli, C., and Ceschin, F. (2009) 'The learning network on sustainability. A mechanism for the development and diffusion of teaching materials and tools on Design for Sustainability in an open-source and copy left logic', paper presented at the Interdisciplinary Seminar "Knowhow: Talent, Knowledge and Interaction”, Lisbon, Portugal, 20-21 March 2009.

Vezzoli, C., Ceschin, F., and M'Rithaa, M. (2009) 'LeNS_AFRICA. An African Learning Network on Sustainability for the development and diffusion of teaching materials and tools on Design for Sustainability in an open-source and copyleft ethos', paper presented at the "4th International Conference on Life Cycle Management", Cape Town, South Africa, 6-9 September 2009.

Vezzoli, C., and Tamborrini, P. (2007) Design per la sostenibilità ambinetale. Strategie e strumenti per la decade, Milan, Libreria Clup.

World Business Council for Sustainable Development (WBCSD) (1996) 'Eco-efficient leadership', Final report of the Working Group on eco-efficiency.

Zaring O. (2001) Creating Eco-Efficient Producer Services, Goteborg, Goteborg Research Institute.

\footnotetext{
${ }^{1}$ Product-Service System (PSS) design, understood as both the design of the mix of products and services jointly capable of fulfilling a given demand, and the design of the interactions among the stakeholders involved in the offer. See for example UNEP (2002), and Vezzoli (2007).

${ }^{2}$ It is a 3 years project started on 15 th December 2007; it is coordinated by Politecnico di Milano University, INDACO Department (Italy) and has as partners Delft University of Technology, Industrial Design Engineering (The Netherlands); University of Art and Design Helsinki, School of Design (Finland); Indian Institute of Technology New Delhi (India); Srishti School of Art, Design and Technology (India); Tsinghua University, Industrial Design Department, Academy of Arts \& Design (China); and King Mongkut's Institute of Technology Ladkrabang, Faculty of Architecture, Department of Industrial Design (Thailand).

${ }^{3}$ See: http://ocw.mit.edu

${ }^{4}$ See: $\underline{\text { http://oli.web.cmu.edu }}$

${ }^{5}$ See: http://www.ocwconsortium.org
} 


\footnotetext{
${ }^{6}$ The initiative involves the London Metropolitan University, the University of Cambridge and the University of Nottingham. See: http://www.rlo-cetl.ac.uk

${ }^{7}$ Project funded by the European Commission. See: http://www.sloopproject.eu

${ }^{8}$ See: http://cnx.org/

${ }^{9}$ Developed within the Calibrate project (funded by the Europen Commission). See: http://lemill.net

10 The $7^{\text {th }}$ of September 2009, prof. Johannes Cronjé, Dean of Faculty of Informatics \& Design (Cape Peninsula University of Technology), has officially launched LeNS Africa, an African Learning Network on Sustainability for curricula development on design for sustainability. The initial partners of LeNS Africa are: Cape Peninsula University of Technology, South Africa (coordinator), University of Botswana, Botswana (co-coordinator); Maseno University, Kenya; University of Nairobi, Kenya; Kwame Nkurumah University of Science and Technology, Ghana; Federal University of Technology, Nigeria; Makerere University, Uganda; University of Zambia, Zambia; and Universitè Polytechnique De Bobo-Dioulasso, Burkina Faso.

${ }^{11}$ In November 2009 prof. Aguinaldo dos Santos (Universidade Federal do Paraná) will officially launch a Brazilian Learning Network on Sustainability, focused on design for sustainability in emerging contexts.
} 